\title{
Los reformuladores de distanciamiento en el corpus PRESEEA de Santiago de Chile*
}

\author{
Abelardo San Martín Núñez ${ }^{* *}$ \\ Universidad de Chile
}

\begin{abstract}
Resumen
El objetivo de este trabajo es ampliar nuestra aproximación variacionista, realizada en San Martín (2004-2005), a un tipo específico de marcador del discurso en el español hablado en Santiago de Chile: los reformuladores de distanciamiento. Para tal propósito, se identificaron las partículas que cumplían la mencionada función en una muestra de 54 entrevistas que conforman el Corpus Sociolingüístico de PRESEEA en Santiago de Chile. Por un lado, se analiza el comportamiento de este tipo de marcadores en la muestra de hablantes santiaguinos antes indicada y, por otro, se establece la distribución de su empleo. Para el estudio de dichas partículas se aplicaron el concepto y la clasificación de los marcadores del discurso de Martín Zorraquino y Portolés (1999) y Portolés (2001), así como las sugerencias de Cortés (1998) y de Carbonero y Santana (2010) para el análisis cuantitativo de su variación social. En el análisis se consideró la función "reformulador de distanciamiento" como un
\end{abstract}

En este artículo se presentan resultados parciales del Proyecto VID SOC 09/18-2, "Variación sintáctica y discursiva del español de Santiago de Chile", financiado por la Vicerrectoría de Investigación y Desarrollo de la Universidad de Chile.

** Para correspondencia, dirigirse a: Abelardo San Martín Núñez (asmartin@uchile.cl), Departamento de Lingüística, Facultad de Filosofía y Humanidades, Universidad de Chile, Ignacio Carrera Pinto 1025, Tercer Piso, Ñuñoa, Santiago, Chile. 
caso de variable sociolingüística con los siguientes valores o variantes (marcadores): igual, de todas maneras, en todo caso y de todas formas. Consecuentemente, se correlacionaron los factores sociodemográficos de los sujetos con el empleo de dichos marcadores. De este modo, basándonos en la conmutabilidad funcional - pragmática y discursivade los marcadores relevados se procedió a su análisis cuantitativo, según las variables: edad, sexo-género y nivel educacional de los sujetos entrevistados.

Palabras clave: análisis del discurso, marcadores del discurso, reformulación, variación discursiva, sociolingüística, español de Chile.

THE REFORMULATION ON DETACHMENT MARKERS IN THE PRESEEA corpus of Santiago, Chile

\begin{abstract}
The aim of this paper is to extend our approach, in San Martín (20042005), to a specific type of discourse marker in spoken Spanish in Santiago de Chile from variationist point of view: the reformulation of detachment markers. For this purpose, the particles that met the above function in a sample of 54 interviews that make up the Sociolinguistic Corpus of PRESEEA in Santiago, Chile were identified. On the one hand, we analyze the behavior of such markers in the range indicated above and, on the other hand, we provide the distribution of employment in a socially stratified sample of Santiago's speakers. For the study of these particles, the Martin Zorraquino \& Portolés (1999) and Portolés (2001) concept and classification of discourse markers, and the suggestions of Cortes (1988) and Carbonero \& Santana (2010) for his social quantitative analysis, is applied. The analysis considered the "reformulation of detachment" as a sociolinguistic variable with the following values or variants (markers): igual, de todas maneras, en todo caso y de todas formas. Consequently, socio-demographic factors were correlated with subjects' use of such markers. Thus, based on the functional-pragmatic commutability of discourse markers registered it preceded its quantitative analysis according to the variables: age, sex-gender and educational level of the interviewees.
\end{abstract}

Key words: discourse analysis, discourse markers, reformulation, discursive variation, sociolinguistics, Chilean Spanish.

Recibido: 29/03/2013 Aceptado: $15 / 05 / 2013$ 


\section{INTRODUCCIÓN}

\section{1. NaturaleZa, objetivos y ALCANCE DEL ESTUdio}

Los marcadores del discurso son unidades de procesamiento que cumplen una función extra-oracional a nivel semántico-pragmático, controlando la situación de enunciación, organizando la información discursiva y guiando la interpretación de los enunciados por parte de los interlocutores (cf. Martín Zorraquino y Portolés 1999, Portolés 2001). El estudio de estas partículas, también denominadas conectores, muletillas, enlaces u ordenadores, ha suscitado un creciente interés en varias lenguas, desde diferentes puntos de vista, por lo que se han transformado en una fructífera temática de estudio dentro del análisis del discurso en varias lenguas (cf. Schiffrin 2003, Loureda y Acín (coords.) 2010). El objetivo general de este estudio es analizar el comportamiento pragmático y la estratificación sociolingüística del empleo de los reformuladores de distanciamiento en una muestra de 54 entrevistas que conforman el Corpus del Proyecto para el Estudio Sociolingüístico del Español de España y América (PRESEEA) correspondiente al habla de Santiago de Chile. De esta manera, pretendemos ampliar la aproximación variacionista que realizamos en San Martín (2004-2005) sobre este tipo específico de marcador, en el español coloquial de Santiago de Chile, con base en otros materiales. Nuestros objetivos específicos son: a) determinar la frecuencia de uso de las partículas que desempeñan la función "reformulación de distanciamiento" en una muestra del corpus PRESEEA de Santiago de Chile, b) correlacionar dichas frecuencias de empleo con los factores sociodemográficos (sexo-género, edad y nivel de educacional) de los informantes cuyas entrevistas conforman dicha muestra y c) contrastar los resultados de este estudio con los de la indagación anterior sobre los reformuladores de distanciamiento. Cabe precisar que, por tratarse de un estudio aproximativo que solo considera la mitad del corpus PRESEEASA, hemos optado por no incluir una prueba de significación estadística. Por lo tanto, en la presentación y análisis de los resultados, se aludirá solo a diferencias porcentuales. 


\section{MARCO CONCEPTUAL}

\section{1. LOS MARCADORES DEL DISCURSO EN LA LENGUA ESPAÑOLA}

En español contamos con excelentes obras de carácter general sobre los marcadores del discurso, como las de Martín Zorraquino y Montolío (coords. 1998), Martín Zorraquino y Portolés (1999), Portolés (2001) y Loureda y Acín (coords. 2010), entre otras. En especial, el estudio de los marcadores del discurso se ha concentrado en la definición y caracterización de estos elementos conectores, así como en la clasificación de las diversas funciones pragmáticas que cumplen en el discurso. Asimismo, existe una serie de monografías que abordan particularmente el funcionamiento discursivo de algunos de los marcadores del discurso en español ${ }^{1}$. En relación con la definición y delimitación funcional de los marcadores del discurso, Portolés (2001: 25-26) señala que son unidades lingüísticas invariables que no ejercen una función sintáctica a nivel oracional y cuya función primordial es orientar las inferencias que se realizan en la comunicación. Para la clasificación de los marcadores en lengua española de acuerdo con su función, resultó fundamental la consulta de las taxonomías de Martín Zorraquino y Portolés (1999) y Portolés (2001). Este último propone los siguientes tipos de marcadores discursivos (adaptado de Portolés 2001: 146): 1) Estructuradores de la información (comentadores, ordenadores y digresores), 2) Conectores (aditivos, consecutivos y contra-argumentativos), 3) Reformuladores (explicativos, de rectificación, de distanciamiento y recapitulativos), 4) Operadores discursivos (de refuerzo argumentativo, de concreción y de formulación) y 5) Marcadores de control de contacto. Para efectos del presente trabajo es pertinente la definición del tipo denominado reformuladores de distanciamiento que, en palabras del mismo autor,

[...] presentan expresamente como no relevante para la prosecución del discurso un miembro del discurso anterior a aquel que los acoge. Con ellos no se pretende formular de nuevo lo antes dicho, sino mostrar la nueva formulación como aquella que ha de condicionar la prosecución del discurso, al tiempo que se priva de pertinencia el miembro discursivo que lo precede (Portolés 2001: 142-143).

\footnotetext{
1 Cortés 1995a y 1995 b ofrece una nutrida bibliografía sobre el estudio de los marcadores del discurso en varias lenguas.
} 
Pertenecen a este grupo de marcadores de todas maneras, de todas formas, en todo caso y en cualquier caso.

Uno de los aspectos aún en desarrollo en la investigación de los marcadores del discurso en lengua española es la dimensión social y dialectal de su uso. En efecto, más allá de las referencias a la posibilidad de incorporar una perspectiva diastrática en Gili Gaya (1972), en los últimos años se han realizado estudios por comunidades como el de Obregón (1985) sobre los marcadores interaccionales en el español de Venezuela, el de Cortés (1991) sobre los marcadores discursivos empleados en León, el de Fuentes (1993) sobre los conectores en el habla de Sevilla o el de Rodríguez (1999) sobre los marcadores discursivos en Baranquilla, así como trabajos sobre marcadores específicos entre los que destacamos los de Serrano (1995, 1999 y 2001). Con todo, las investigaciones de conjunto que aborden la distribución social y espacial de estos enlaces extra-oracionales de manera sistemática, en el dominio hispánico, están todavía en ejecución ${ }^{2}$.

Por lo que se refiere al estudio de las "muletillas" o de los marcadores del discurso en el español hablado en Chile, contamos con los trabajos de Rabanales y Contreras (1991), Pons y Samaniego (1998), Pérez (1998), Poblete (1998 y 1999), Meneses (2000) y González et al. (2000), entre otros ${ }^{3}$.

2 Para una revisión crítica de los estudios sobre la variación dialectal y social de los marcadores del discurso recomendamos a Carbonero y Santana (2010).

Rabanales y Contreras (1991) estudian las funciones de las muletillas en el habla culta de Santiago de Chile. Además de proporcionar una clasificación de las funciones de las muletillas en una muestra de diálogos informales de hablantes cultos, los autores entregan datos cuantitativos sobre su empleo, según las variables: edad y sexo, resultando ser los jóvenes y los hombres los que más emplean muletillas. Por otro lado, Pons y Samaniego (1998) estudian los marcadores de apoyo empleados en una muestra de discurso oral de hablantes cultos de Santiago de Chile. Se analizan 29 marcadores de apoyo discursivo, según tres grupos etarios y la variable sexo (mujer/hombre) en el discurso de 10 sujetos. Los conectores textuales a nivel de parágrafo, por otra parte, se describen en Pérez (1998), quien señala que el tipo de texto (expositivo o argumentativo) en el parágrafo influye en los conectores empleados. Más allá de la descripción del habla capitalina, Poblete (1998 y 1999) estudia los marcadores del discurso empleados en Valdivia. En el primero de dichos trabajos, la autora identifica los marcadores conversacionales más frecuentes en una muestra representativa del habla de Valdivia compuesta por entrevistas semiformales. Se describen 75 marcadores conversacionales de acuerdo con su función y frecuencia de uso, sin embargo no se formulan observaciones respecto de la influencia de variables sociodemográficas. Posteriormente, en Poblete (1999) se estudian la distribución y ocurrencia de los marcadores que establecen coherencia (llamados "relacionantes") en secuencias discursivas de diferente tipo (descriptiva, narrativa, expositiva y argumentativa), presentes en 18 entrevistas semiformales. Los resultados obtenidos respecto de dicha distribución por tipo de discurso se relacionaron con las variables sociales: estrato social, sexo y edad. Por otro lado, Meneses (2000) y González et al. (2000) 


\section{2. El ESTUdio SOCIOLINGÜístico DE LOS MARCADORES DEL DISCURSO}

En este estudio sugerimos la posibilidad de considerar el empleo de los marcadores del discurso como un caso de variable lingüística -en un sentido amplio del concepto- a nivel de discurso. Por lo tanto, un aspecto a tener en consideración es el problema de la extensión del ámbito de aplicación del concepto de variable sociolingüística más allá del plano fonético ${ }^{4}$ hacia el ámbito discursivo. Como es sabido, en el marco del paradigma cuantitativo laboviano más clásico, una exigencia para la aplicación de este concepto era que las formas alternantes no conllevaran diferencias semánticas y, de esta manera, consistieran en "dos o más formas diferentes de decir lo mismo" (Labov 1972). No obstante, con posterioridad a este debate, se ha defendido la necesidad de relativizar la exigencia de igualdad semántica de las variantes y reemplazarla por un criterio de comparabilidad o equivalencia funcional o pragmática (Lavandera 1978, Romaine 1981, Silva-Corvalán 2001 y Serrano 2007 y 2011), que está en el centro de la fundamentación de este trabajo. Por su parte, Carbonero y Santana (2010: 516-517) señalan la carencia de trabajos que aborden la variación espacial y social de los marcadores del discurso, aunque -al mismo tiempo- destacan el interés de esta línea de trabajo para el mejor conocimiento de estas unidades de procesamiento.

En principio, la variación lingüística "definida como el uso alterno de formas diferentes de decir lo mismo se puede encontrar prácticamente en todos los niveles de la lengua, desde el más concreto (fonético-fonológico) al más amplio (discurso, por ejemplo), pasando por la gramática y el léxico" (Moreno Fernández 1998: 19). Por ello, la ampliación de los estudios variacionistas al plano discursivo no está descartada de antemano. En relación con el problema que nos ocupa, Cortés (1998) aborda, en particular, la posibilidad de llevar a cabo un estudio cuantitativo de los marcadores del discurso. Según Cortés, pese a las limitaciones que se ha impuesto al estudio

plantean discusiones bibliográficas en torno a los marcadores discursivos característicos de la conversación coloquial.

La extensión del concepto de variable sociolingüística al estudio de fenómenos de variación sintáctica planteó una serie de dificultades, especialmente, a partir del trabajo de Lavandera (1978) en el que se cuestionó explícitamente dicha extensión, arguyendo que no estaba garantizado en el estudio de dichas variables el principio de invariabilidad a nivel semántico, imprescindible para la consideración de una variable sociolingüística. Para mayor detalle en cuanto al desarrollo de esta controversia, cf. Lavandera (1978), Labov (1978), García (1986), Prieto (1995-1996), Silva-Corvalán (2001), Romaine (1981), Sankoff (1988), López Morales (2004), Blas Arroyo (2005), Moreno Fernández (1998) y Serrano (1999, 2007 y 2011). 
variacionista de los marcadores del discurso, la variabilidad de los mismos no está bajo cuestionamiento, ya que,

[t]oda elección de un marcador, como la de cualquier otro fenómeno fónico, gramatical o léxico, puede venir condicionada bien por una serie de circunstancias estilísticas -registros más o menos formales-, bien por la pertenencia del hablante a un determinado grupo sociocultural -nivel de cultura, edad, sexo-, bien por la modalidad -oral, escrita-, etc. (Cortés 1998: 152).

En efecto, el mismo autor proporciona algunos datos de su propia indagación respecto de los condicionamientos socioculturales que inciden en el uso de o sea que y de modo que o de manera que en el español oral de León; según los cuales o sea que es empleado -mayoritariamente-por hablantes leoneses jóvenes y de menor cultura, mientras que de modo que y de manera que los utilizan sujetos de mayor edad y nivel educacional. Ahora bien, con base en otros estudios cuantitativos de los marcadores y la discusión en torno a la capacidad heurística del concepto de variable sociolingüística, Cortés (1998: 153) se pregunta si puede estudiarse el marcador como variable. A este respecto, basado en Romaine y Winford, Cortés señala que un análisis cuantitativo o sociolingüístico de los marcadores del discurso es posible solo si se logra determinar que dos o más formas de este tipo resultan estar en "distribución complementaria" respecto de los factores sociodemográficos de los hablantes. En rigor, entonces, un análisis variacionista de los marcadores es posible en la medida en que se correlacionen dichos factores con formas que cumplen una misma función en el discurso:

Existe la idea, cada vez más aceptada, de que la extensión del análisis variacionista al nivel sintáctico lleva consigo una nueva consideración en cuanto a la equivalencia semántica de las variantes: las variables del discurso se pueden determinar a partir de una función común en el discurso (Cortés 1998: 154).

Por ello, previo al estudio cuantitativo de los marcadores, es necesario que estudios de tipo cualitativo-pragmático identifiquen -precisamente- cuáles son esas funciones pragmáticas compartidas por dos o más formas alternantes en el discurso (Cortés 1998: 155). Finalmente, Cortés concluye que el estudio variacionista de los marcadores es posible si se cumple el fuerte requisito de contrastar las frecuencias de conectores que cumplan las mismas funciones, lo que trae aparejadas no pocas dificultades en el análisis de estos elementos (Cortés 1998: 160). 
En síntesis, en el caso de los marcadores del discurso, una aproximación sociolingüística a su empleo requiere de un análisis pragmático-discursivo previo que identifique las funciones desempeñadas por dichas formas y correlacione las frecuencias de uso de marcadores alternantes, respecto de una misma función, con los factores sociodemográficos de los hablantes. En nuestra opinión, más allá de las limitaciones que plantean Cortés (1988) y Carbonero y Santana (2010), la aplicación del concepto de variable sociolingüística al estudio de los marcadores del discurso es promisoria, ya que, en virtud de su estatus pragmático, los marcadores que cumplen una misma función satisfarían la condición de ser variantes pragmáticamente equivalentes, es decir, se trataría de formas alternativas de comunicar lo mismo. El problema radica, más bien, en identificar con precisión las funciones discursivas "variables" y sus correspondientes marcadores o "variantes" en una muestra representativa y estratificada de sujetos de una determinada comunidad de habla. Para este propósito, resulta de fundamental utilidad recurrir a la prueba de la conmutación entre marcadores diferentes, tal como sugiere Portolés (2001: 79-84). Este procedimiento analítico fue ya empleado con provecho en nuestro estudio anterior sobre los reformuladores de distanciamiento en el habla de Santiago de Chile (San Martín 2004-2005) .

\section{METODOLOGÍA}

\subsection{CORPUS}

El corpus que sirvió de base para el análisis del presente estudio consistió en 54 entrevistas sociolingüísticas que corresponden a la mitad del corpus de Santiago de Chile en el Proyecto para el Estudio Sociolingüístico del Español de España y América (PRESEEA) ${ }^{6}$. Para la recopilación del

\footnotetext{
5 Por lo que atañe al estudio de la variación discursiva en el habla de Santiago de Chile, en general, la perspectiva adoptada en el presente artículo ha sido también desarrollada en otros estudios -además del ya citado- sobre: a) las diferencias de género en el empleo del discurso referido en el estrato bajo (Prieto y San Martín 2002-2003), b) los marcadores interrogativos de control de contacto (San Martín 2011) y c) la estratificación social del empleo del discurso referido (San Martín y Guerrero 2013), estos dos últimos con materiales del PRESEEA.

${ }^{6}$ El equipo de PRESEEA en Santiago de Chile está compuesto por los profesores de la Universidad de Chile, Alfredo Matus Olivier (coordinador) y Abelardo San Martín Núñez y Silvana Guerrero González (investigadores).
} 
corpus sociolingüístico de PRESEEA en Santiago de Chile, se aprovechó la instancia de aplicación de un instrumento que, para fines de la investigación sociolingüística del habla de la mencionada ciudad, se realiza anualmente desde 1978 hasta la fecha, en el marco de la asignatura de Sociolingüística que se imparte en las Licenciaturas en Lengua y Literatura Hispánica y Lengua y Literatura Inglesas de la Universidad de Chile ${ }^{7}$. Las entrevistas fueron hechas a hombres y mujeres con características socio-demográficas congruentes, aplicando los supuestos metodológicos sugeridos por Labov (1972). Consecuentemente, en dichas situaciones los entrevistadores debían tratar de superar la "paradoja del observador" consiguiendo, de esta forma, una muestra significativa de discurso natural grabado (estilo vernacular) de hablantes representativos de la comunidad de habla en estudio. En las instrucciones a los entrevistadores se enfatizó que durante la entrevista debía generarse un clima de confianza, a fin de obtener el estilo de habla más espontáneo o natural del sujeto. Asimismo, se les indicó que, idealmente, los hablantes debían olvidarse de que estaban siendo grabados y debían comportarse de modo espontáneo como si estuvieran participando en una conversación natural.

\subsubsection{Población de la muestra}

Para la conformación de la muestra de sujetos entrevistados se consideró la población santiaguina que cumpliera con los siguientes criterios de asignación de estatus de hablante nativo de Santiago de Chile: 1) haber nacido y residido en forma ininterrumpida en Santiago; 2) haber residido en forma ininterrumpida en Santiago desde los cinco años de edad; y 3) haber nacido en Santiago y haber residido en Santiago la mayor parte de sus vidas, salvo por periodos que sumados no superen los cuatro años en el tramo de 50 años y más y los tres años en el tramo de 35 a 49 años (Prieto 1995-1996: 389-398). El cuestionario de la entrevista se aplicó a una muestra de sujetos del tipo denominado "muestra por cuotas con afijación uniforme" (López Morales 1994), en la que se divide a la población en estratos o categorías y se asigna una cuota a cada uno de los distintos estratos. La muestra así conformada comprende un total de 54 individuos, distribuidos proporcionalmente como se indica en la Tabla 1 que se incluye a continuación.

\footnotetext{
Dicho instrumento fue implementado por el profesor Luis Prieto Vera, quien estuvo a cargo de la mencionada asignatura entre 1978 y 2009.
} 
Tabla 1: Distribución de sujetos de la muestra por nivel educacional, sexo y edad, según PRESEEA

\begin{tabular}{|l|c|c|c|c|c|c|c|}
\hline \multicolumn{7}{|c|}{ Grupo de edad } \\
\hline $\begin{array}{l}\text { Nivel } \\
\text { educacional }\end{array}$ & \multicolumn{2}{|c|}{$20-34$} & \multicolumn{2}{c|}{$35-54$} & \multicolumn{2}{c|}{55 y más } & Totales \\
\cline { 2 - 7 } & $\mathrm{H}$ & $\mathrm{M}$ & $\mathrm{H}$ & $\mathrm{M}$ & $\mathrm{H}$ & $\mathrm{M}$ & \\
\hline Alto & 3 & 3 & 3 & 3 & 3 & 3 & 18 \\
\hline Medio & 3 & 3 & 3 & 3 & 3 & 3 & 18 \\
\hline Bajo & 3 & 3 & 3 & 3 & 3 & 3 & 18 \\
\hline Totales & 9 & 9 & 9 & 9 & 9 & 9 & 54 \\
\hline
\end{tabular}

\subsubsection{Procedimiento de estratificación empleado}

Siguiendo el sistema de estratificación del Proyecto PRESEEA, se estratificó a la muestra de sujetos de acuerdo con sus respectivos niveles de instrucción, es decir, según la equivalencia entre los niveles de estudios básico, secundario y superior con los estratos bajo, medio y alto, respectivamente. Sin embargo, con el propósito de garantizar la homogeneidad en la composición de los distintos estratos de la muestra y, por tanto, la representatividad de los mismos en relación con la población analizada, se complementó dicho sistema de estratificación con el procedimiento de estratificación empleado por el proyecto de Estudio Sociolingüístico del Español de Chile $(\mathrm{ESECH})^{8}$, que se basa en el procedimiento sugerido por Prieto (1995-1996). Dicho sistema de estratificación considera una escala de estatus socioeconómico que contempla las siguientes variables independientes: nivel educacional, categoría ocupacional y calidad ambiental de la zona de residencia. Asimismo, para asegurar la rigurosidad de la clasificación socioeconómica de los integrantes de la muestra, se tuvo en cuenta la estratificación social elaborada en 2008 por la Asociación chilena de empresas de Investigación de Mercado (AIM), la descripción básica de grupos socio-económicos realizada por la empresa ICCOM en 2007, así como la información específica proporcionada en 2003 por la empresa ADIMARK. De este modo, se escogieron las entrevistas realizadas a aquellos sujetos que, tras la aplicación de la escala de estratificación social, mostraban lo que Lenski (1954 y 1956) ha denominado cristalización o congruencia de estatus 9 .

\footnotetext{
8 ESECH es un grupo de investigación de la Universidad de Chile al que pertenecen los miembros del Equipo PRESEEA-Santiago.

$9 \quad$ Según Lenski (1954 y 1956), se considera que un individuo es congruente con su estatus cuando las puntuaciones obtenidas en las diferentes dimensiones usadas para medir
} 
En la Tabla 2, se especifican las características socio-demográficas de cada uno de los integrantes de la muestra, clasificados de acuerdo con su sexo-género, grupo etario y nivel educacional.

Tabla 2: Características socio-demográficas de los integrantes de la muestra

\begin{tabular}{|c|c|c|c|c|c|c|c|c|}
\hline Estrato & \begin{tabular}{|c|} 
Grupo \\
de \\
edad
\end{tabular} & Sexo & Código $^{10}$ & $\begin{array}{c}\text { Duración } \\
\text { de la } \\
\text { entrevista }\end{array}$ & \begin{tabular}{|c|} 
Año \\
de \\
naci- \\
miento
\end{tabular} & \begin{tabular}{|l} 
Nivel \\
Edu- \\
cacio- \\
nal $^{11}$ \\
\end{tabular} & $\begin{array}{l}\text { Profesión u } \\
\text { ocupación }\end{array}$ & $\begin{array}{l}\text { Comuna de } \\
\text { residencia }\end{array}$ \\
\hline \multirow{12}{*}{ 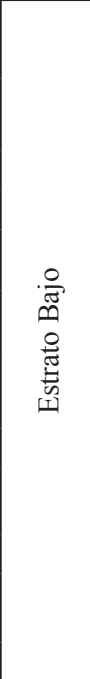 } & \multirow{6}{*}{$\begin{array}{l}20-34 \\
\text { años }\end{array}$} & \multirow[t]{3}{*}{$\mathrm{H}$} & SCHI_H11_001 & $57^{\prime} 40^{\prime \prime}$ & 1983 & BI & $\begin{array}{l}\text { Guardia de } \\
\text { seguridad }\end{array}$ & La Pintana \\
\hline & & & SCHI_H11_002 & $66^{\prime} 43^{\prime \prime}$ & 1984 & MI & $\begin{array}{l}\text { Reparador de } \\
\text { computadores }\end{array}$ & Maipú \\
\hline & & & SCHI_H11_003 & $76^{\prime} 13^{\prime \prime}$ & 1982 & MI & Cesante & El Bosque \\
\hline & & \multirow{3}{*}{ M } & SCHI_M11_007 & 63'53"' & 1977 & $\mathrm{BI}$ & Cesante & La Cisterna \\
\hline & & & SCHI_M11_008 & $58^{\prime} 13^{\prime \prime}$ & 1980 & MI & Dueña de casa & E1 Bosque \\
\hline & & & SCHI_M11_009 & $51^{\prime} 10^{\prime \prime}$ & 1976 & $\mathrm{BC}$ & Dueña de casa & \begin{tabular}{|l|} 
Quinta \\
Normal
\end{tabular} \\
\hline & \multirow{6}{*}{$\left|\begin{array}{l}35-54 \\
\text { años }\end{array}\right|$} & \multirow[t]{3}{*}{$\mathrm{H}$} & SCHI_H21_013 & $55^{\prime} 54^{\prime \prime}$ & 1966 & MI & $\begin{array}{l}\text { Cuidador de } \\
\text { caballos }\end{array}$ & Independencia \\
\hline & & & SCHI_H21_014 & 61'37 & 1961 & $\mathrm{BI}$ & Yesero & Cerro Navia \\
\hline & & & SCHI_H21_015 & $46 ’ 06 "$ & 1951 & MI & $\begin{array}{l}\text { Transportista } \\
\text { escolar }\end{array}$ & La Florida \\
\hline & & \multirow{3}{*}{ M } & SCHI_M21_019 & 60'53”' & 1959 & $\mathrm{BI}$ & Comerciante & La Pintana \\
\hline & & & SCHI_M21_020 & $57^{\prime} 56^{\prime \prime}$ & 1969 & MI & $\begin{array}{l}\text { Auxiliar } \\
\text { de aseo }\end{array}$ & $\begin{array}{l}\text { Estación } \\
\text { Central }\end{array}$ \\
\hline & & & SCHI_M21_021 & $55^{\prime} 57$ & 1961 & $\mathrm{BI}$ & Niñera & Puente Alto \\
\hline
\end{tabular}

el estatus, son más o menos iguales, independiente de que sus rangos sean altos, bajos o estén en una extensión media. Cuando las puntuaciones del individuo son muy diferentes, se habla de incongruencia de estatus.

10 El código de los sujetos tiene las siguientes equivalencias: SCHI: Santiago de Chile; Sexo $=\mathrm{H}$ (hombre) y $\mathrm{M}$ (mujer). El primer número que le sigue a dichas equivalencias corresponde al código del grupo de edad: $1=20$ a 34 años, $2=35$ a 54 años y $3=55$ años y más; el segundo número corresponde al nivel educacional: $1=$ Bajo (sin estudios o con instrucción primaria o instrucción secundaria incompleta), $2=$ Medio (con instrucción secundaria) y $3=$ Alto (con instrucción superior). Los dígitos finales corresponden a numeración correlativa que se le asignó a los sujetos en el corpus PRESEEA Santiago de Chile.

11 Las siglas de esta columna tienen las siguientes equivalencias: UC = educación universitaria completa; UI = educación universitaria incompleta; TPC = educación técnicaprofesional completa; TPI = educación técnica-profesional incompleta; $\mathrm{MC}=$ educación media completa; $\mathrm{MI}=$ educación media incompleta; $\mathrm{BC}=$ educación básica completa; $\mathrm{BI}=$ educación básica incompleta. 


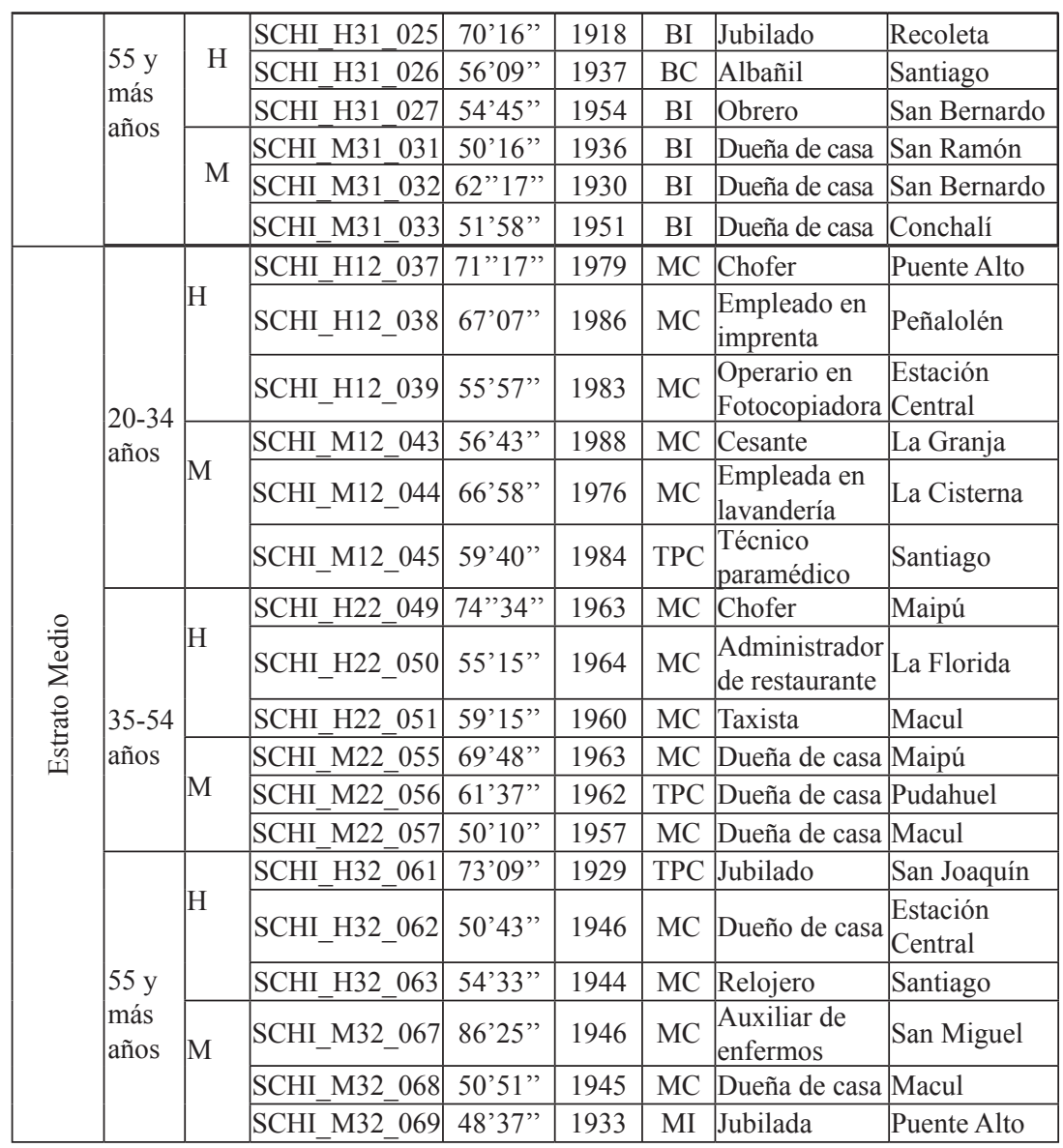




\begin{tabular}{|c|c|c|c|c|c|c|c|c|}
\hline \multirow{18}{*}{ 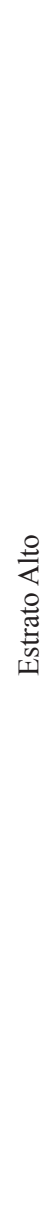 } & \multirow{6}{*}{$\begin{array}{l}20-34 \\
\text { años }\end{array}$} & \multirow[t]{3}{*}{$\mathrm{H}$} & SCHI_H13_073 & $59^{\prime} 00^{\prime \prime}$ & 1983 & UI & $\begin{array}{l}\text { Constructor } \\
\text { civil }\end{array}$ & Providencia \\
\hline & & & SCHI_H13_074 & $52^{\prime} 06^{\prime \prime}$ & 1985 & UI & $\begin{array}{l}\text { Estudiante } \\
\text { diseño } \\
\text { industrial } \\
\text { de sonido }\end{array}$ & Providencia \\
\hline & & & SCHI_H13_075 & $51^{\prime} 49^{\prime \prime}$ & 1986 & UI & $\begin{array}{l}\text { Estudiante } \\
\text { de sonido }\end{array}$ & Santiago \\
\hline & & \multirow[t]{3}{*}{ M } & SCHI_M13_079 & $71 ’ 38^{\prime \prime}$ & 1980 & UI & $\begin{array}{l}\text { Estudiante } \\
\text { Licenciatura } \\
\text { Inglesa }\end{array}$ & Santiago \\
\hline & & & SCHI_M13_080 & $51^{\prime} 45^{\prime \prime}$ & 1985 & UC & $\begin{array}{l}\text { Traductora } \\
\text { e intérprete } \\
\text { en inglés }\end{array}$ & Ñuñoa \\
\hline & & & SCHI_M13_081 & $50 ’ 22^{\prime \prime}$ & 1977 & $\mathrm{UC}$ & Psicóloga & Ñuñoa \\
\hline & \multirow{6}{*}{$\begin{array}{l}35-54 \\
\text { años }\end{array}$} & \multirow[t]{3}{*}{$\mathrm{H}$} & SCHI_H23_085 & $52^{\prime} 58^{\prime \prime}$ & 1964 & UC & $\begin{array}{l}\text { Químico } \\
\text { farmacéutico }\end{array}$ & Peñalolén \\
\hline & & & SCHI_H23_086 & $50 ’ 02 ”$ & 1958 & UC & $\begin{array}{l}\text { Director de } \\
\text { colegio }\end{array}$ & La Cisterna \\
\hline & & & SCHI_H23_087 & $57 ’ 26 ”$ & 1964 & UC & $\begin{array}{l}\text { Director de } \\
\text { orquesta y } \\
\text { productor } \\
\text { musical } \\
\end{array}$ & Macul \\
\hline & & \multirow{3}{*}{$\mathrm{M}$} & SCHI_M23_091 & $57^{\prime} 37^{\prime \prime}$ & 1973 & $\mathrm{UC}$ & Abogado & Providencia \\
\hline & & & SCHI_M23_092 & 62'54"' & 1956 & $\mathrm{UC}$ & Nutricionista & Ñuñoa \\
\hline & & & SCHI_M23_093 & $63^{\prime} 55^{\prime \prime}$ & 1960 & UI & $\begin{array}{l}\text { Decoradora } \\
\text { de interiores }\end{array}$ & Ñuñoa \\
\hline & \multirow{6}{*}{$\begin{array}{l}55 \text { y } \\
\text { más } \\
\text { años }\end{array}$} & \multirow[t]{3}{*}{$\mathrm{H}$} & SCHI_H33_097 & $60 ’ 41^{\prime \prime}$ & 1937 & UI & $\begin{array}{l}\text { Profesor de } \\
\text { aviación }\end{array}$ & Macul \\
\hline & & & SCHI_H33_098 & $46 ' 57^{\prime \prime}$ & 1952 & UC & $\begin{array}{l}\text { Ingeniero } \\
\text { comercial }\end{array}$ & Ñuñoa \\
\hline & & & SCHI_H33_099 & $55^{\prime} 11 "$ & 1947 & $\mathrm{UC}$ & Químico & Ñuñoa \\
\hline & & \multirow{3}{*}{$\mathrm{M}$} & SCHI_M33_103 & 64'18" & 1931 & $\mathrm{UC}$ & Psiquiatra & Vitacura \\
\hline & & & SCHI_M33_104 & 60’37'” & 1952 & UC & Médico & Providencia \\
\hline & & & SCHI_M33_105 & $55^{\prime} 45^{\prime \prime}$ & 1947 & UC & Kinesióloga & Santiago \\
\hline
\end{tabular}

\section{PRESENTACIÓN Y ANÁLISIS DE LOS RESULTADOS}

\subsection{ANÁLISIS PRAGMÁtico DE LOS REFORMULADORES DE DISTANCIAMIENTO EN EL CORPUS PRESEEA-SA}

Para el cumplimiento de la función "reformulador de distanciamiento", en nuestro corpus, se identificó el empleo de cuatro partículas: igual, de todas 
maneras, en todo caso y de todas formas. Se trata de un repertorio casi idéntico al que relevamos anteriormente, al que ahora se agrega el marcador de todas formas. En general, se trata de partículas cuya función reformuladora y de distanciamiento ha sido ya reconocida en otras variedades del español, a excepción de igual. Como destacamos en San Martín (2004-2005), a nuestro juicio, el valor discursivo de igual tiene su origen en un proceso de gramaticalización ${ }^{12} \mathrm{o}$, más bien, de discursivización, muy semejante al que otros elementos gramaticales han sufrido hasta convertirse en partículas discursivas. La base de esta gramaticalización estaría en la analogía semántica entre igual y todo que podemos extrapolar a las locuciones de igual manera (forma) y de todas maneras (formas). Este sentido cercano, que también implica la consideración de igualmente como un elemento de doble funcionalidad: como adverbio comparativo y como reformulador de distanciamiento, explicaría la extensión semántica desde Igual-Adverbio a Igual-Marcador. Por supuesto, a favor de la divulgación de este uso discursivo de igual ha sido determinante su brevedad lo que, desde un punto de vista funcionalista lo convierte en una manera económica y mucho más simple de expresar distanciamiento que de todas maneras, en todo caso y de todas formas ${ }^{13}$.

En los ejemplos 1 a 3 puede apreciarse el funcionamiento de igual como reformulador de distanciamiento identificado en el corpus PRESEEA-SA ${ }^{14}$ :

1. E: ya ee ¿satisface tu actual trabajo las expectativas que te habías forjado/ al terminar la enseñanza media? I: ee yo/ lo que yo quería era ser independiente/ igual soy como independiente/ pero igual tengo que responderle a una señora que es/ es la dueña del auto/ pero por ejemplo/ cuando trabajé con mi furgón/ era diferente/ igual gané plata y todo/ pero yo quería/ que el furgón me diera/ que yo a él lo podía meter en una empresa buena/ pero nunca lo pude hacer/ nunca se me dio la/ la oportunidad/ entonces yo quería ser siempre/ hubiese querido ser siempre

12 Cf. Brinton y Traugott 2005 y Company 2004 para la explicación del origen de los marcadores del discurso como resultado de procesos de gramaticalización.

13 Para un mayor detalle sobre nuestra propuesta de explicación del proceso de gramaticalización de igual remitimos a San Martín (2004-2005).

14 Respecto de la transcripción de los ejemplos, es necesario señalar las siguientes convenciones gráficas: 1) $\mathrm{E}=$ entrevistador e $\mathrm{I}$ = informante; 2) el texto correspondiente a cada entrevista se transcribe en ortografía convencional, incluidos los acentos gráficos; 3 ) para la mejor comprensión de los ejemplos incluidos en este artículo, se ha suprimido el sistema de etiquetas que se emplean en la transcripción de las entrevistas de PRESEEA, excepto las pausas. 
independiente/ haber tenido $\mathrm{mi} / \mathrm{mi}$ vehículo trabajando en un lugar bueno// haber tenido una pega estable/ pero no se dio/ pero este trabajo/ igual me gusta/ yy lo hago con agrado// igual salvan las luquitas que te dan (SCHI H12 037).

2. E: ¿y cómo te llevái con tus vecinos?/ ¿tení amigos ahí en el barrio huevón? ¿O no? I: ¿en el barrio?/ hartos conocidos po huevón/ vecinos con algunos hablamos no más po huevón/igual es como/ son tan repiolas que no salen po huevón/ y eso es lo que ha cambiado/ antes/ igual como que se conocían más todos/ pero después como que empezó/ yo creo que en todos lados po huevón/ en todos/ igual pasa lo mismo que antes/ igual uno conocía/ hacía sus fiestas/ o igual que pasa lo mismo en Año Nuevo po/ antes todos iban a las casas de todos/ pero ahora como que/ poco/ poco pasa esa cuestión/ porque/ hay poca conexión E: pero/ ¿tu relación se limita a un saludo con tus vecinos y eso sería? I: un saludo/ y con algunos y una conversación/ sus tallas ¿cachái?/ pero ya un carrete así entre vecinos/ no/ es que aparte que los vecinos/ igual son como más viejos po huevón/ entonces son como demasiado/ entonces yo uno para/ yo carreteo en otra en otra población po/ yo voy para Nogales ¿cachái?/ para esos lados entonces yo paso poco en la población po (SCHI H12 039).

3. E: ¿qué pensabas cuando/ o sea cuáles eran tus expectativas? I: (...) o sea el tema de la traducción es mucho más estable/ fue mucho más estable ahora que estoy con el tema de la interpretación/ sí/ es más esporádico/ pero igual/ es todas las semanas/igual me pagan bien/igual es/ sí/ y yo creo que he tenido muchas más oportunidades de lo que mucha gente/ que ha estudiado mi carrera ha tenido/ no sé si las he aprovechado. E: ¿ee juegas a la lotería o al kino? I: no. E: ¿por qué? I: porque es un gasto en plata/ no me lo voy a ganar/ a menos/ juego cuando hay/ tres mil millones de pesos porque digo/ "bueno aunque nos ganemos de tres personas/igual va a ser bueno entre diez personas/ igual va a ser bueno" (SCHI M13 080).

En los ejemplos anteriores, destaca el empleo de igual en la forma de encadenamientos de reformulación que van relativizando las afirmaciones precedentes, respecto del grado de satisfacción, laboral en 1 y 3 , y vecinal en 2, de los informantes. Es destacable en 2, asimismo, la diferencia entre igual en su empleo como adjetivo comparativo de igualdad y los usos de igual como reformulador de distanciamiento, conmutable por de todas maneras (formas) y en todo caso.

A pesar de la frecuencia del empleo de igual como marcador del discurso, cabe destacar que este uso no ha sido objeto de atención especial en el análisis del discurso oral del español de Chile, más allá de nuestra indagación previa 
(San Martín 2004-2005). En el DUECH, por ejemplo, no se consigna su valor como reformulador de distanciamiento; solo se hace referencia a la locución adverbial igual Pascual (s. v. igual Pascual), que corresponde a una fórmula festiva. Solo en el último tiempo, Fant (2011: 125-126) analiza el marcador igual como parte de los recursos de modalización de expresión de la subjetividad del hablante en el discurso oral, destacando su valor concesivo y su uso frecuente en el español de Chile. Este rasgo, según el autor citado, diferenciaría a esta variedad de otras como la peninsular y la rioplatense, en las que igual tendría más bien un valor dubitativo semejante a tal vez (Fant 2011: nota 4). No obstante, el DA consigna un valor concesivo para igual en diferentes variedades del español americano, incluida la chilena, con el significado "a pesar de todo, no obstante" (DA, s. v. igual) ${ }^{15}$.

Por otro lado, en los ejemplos 4 y 5 ejemplificamos el empleo de de todas maneras como reformulador de distanciamiento en el corpus:

4. E: aa claro. I: ¿entiendes tú?/ de los que más pagan -E: sí po. -I: de todas maneras poco/ lo que pagan/ pero/ ese es el otro problema po/ o sea ese problema del FONASA actual comparado con las ISAPRE/ es que si yo me tengo que hacer una operación/ qué sé yo/ no sé po/ tengo un accidente grave y voy a dar a la UCI/ a la unidad de cuidados intensivos/ y tengo que estar una semana ahí/ ¿tú sabes la cuenta que me sale en una UCI/ súper grande/ ¿y cuánto me cubre a mi FONASA de eso?/ la nada misma po. E: aa. I: entonces en el fondo tengo que/ tengo que casi pagarlo de mi bolsillo. E: mm. I: ahora/ si tú tienes un sueldo/ que te alcanza para estar en un buen plan de una ISAPRE/ un buen plan en que te digan "si usted se va a tales y tales clínicas o a tales y tales hospitales/ nosotros le vamos a pagar el ochenta por ciento de su hospitalización"/ a lo mejor me conviene más po. E: claro. I: aunque yo sé que el día/ el día de hospitalización/ en una clínica es muchísimo más caro que el día de hospitalización en un hospital/ pero de todas maneras me van a pagar el ochenta por ciento (SCHI M33 104).

5. I: (...) últimamente como yo estoy media patuleca/ ee// y/y ee/ no ando en/ no ando en/ en locomoción colectiva/ eeh / me gasto unos pesos y no me meto. E: $\mathrm{mm}$. I: ¿mm? E: ahora viene la última pregunta. I: de/ de todas maneras/me sale más barato que andar en auto. E: en auto/ sí. I: mm. E: la bencina es muy cara (SCHI M33 103).

15 Hummel (2012) estudia la polifuncionalidad de igual, analizando sus valores como adjetivo y como marcador del discurso en materiales del español de Chile. También destaca la falta de atención sobre el comportamiento de igual como marcador del discurso (Hummel, 2012: 89), aunque no alude a nuestro trabajo anterior (San Martín 2004-2005). 
En estos ejemplos, nos encontramos con un empleo menos constante o prolífico de la función de reformulación de distanciamiento, en contraste con el que se evidencia mediante el marcador igual. En 4 el informante contrasta la calidad de la atención en la salud pública con la privada, mientras que en 5 se relativiza la conveniencia de movilizarse en automóvil en vez de en transporte colectivo.

Asimismo, el uso de en todo caso como reformulador de distanciamiento se ilustra con los ejemplos 6 y 7 :

6. E: ya// pero y tú cuando terminaste la carrera eeh/ tú ee ¿en qué pensabái que ibái a trabajar?/ ¿que ibái a hacer investigación? I: en una industria no/ en una empresa en en algo más aplicado// pero eso casi no existía// en todo caso/ la carrera que estudié era amorfa bastante amorfa y sigue siendo igual (SCHI H33 099).

7. E: ¿seguiste regularmente "Amor ciego" de canal trece? I: sí// me vi todos los capítulos// no me perdí ninguno/ me gusta Edmundo. E: ¿con quién te hubiese gustado que se quedara Carolina? I: sí/ con Edmundo// pero la mina es muy zorra así que no. E: ¿qué te pareció ese programa en general? I: una mierda// cero aporte// pero entretenida en todo caso (SCHI M12 045).

En los ejemplos antes presentados los informantes se distancian de su afirmación precedente mediante en todo caso, presentando una crítica a su propia formación profesional en 6 y rescatando la entretención proporcionada por los reality show en 7. También es destacable en 6 el contraste entre igual como adjetivo comparativo de igualdad y los usos relevados de igual como marcador en los ejemplos 1 a 3.

Por último, el ejemplo 8 fue el único caso registrado del reformulador de distanciamiento de todas formas en nuestros materiales:

8. E: ya ¿serías capaz de perdonar un caso de infidelidad por parte de tu polola/ o pareja? I: mmm no/ no eeh / no sé yo creo que soy súper/ demasiado rencoroso// con cualquier persona que me haga cualquier cosa/ yo creo que la mentira y la traición son ya/ no no la podría aguantar/ o sea me haría personalmente mucho daño a mí y y no podría olvidar aunque quisiera. E: claro. I: tengo una memoria súper selectiva y generalmente/ tiendo a recordar esas cosas/ creo que una forma de protegerse/ personalmente creo que es una forma en que uno se protege/ o sea acordándose de las cosas malas que le hicieron los otros/ entonces/ creo poco/ quizás claro uno se puede arrepentir y todo pero el daño ya está hecho/ o sea. E: claro aunque uno perdone/ igual las cosas no se olvidan. I: claro iguall de todas formas claro si yo hiciera lo mismo// yo 
tampoco me podría perdonar a mí mismo entonces no podría mirar a la persona de la misma forma o sea no/ no se no son cosas que son como que son no no// pero quizás hay gente que lo hace// hay gente quizás/ puede entender// esos comportamientos pero cuando uno quiere tanto a una persona/ no es capaz de hacer tanto daño/ y yo creo que no hay cosa que dañe más que eso (SCHI H13 073).

En este ejemplo, el informante fundamenta su postura frente a la infidelidad de una pareja como una falta imperdonable. No obstante, llama la atención el hecho de que en el ejemplo el marcador de todas formas se encuentre reforzando la función de igual como reformulador de distanciamiento, lo que nos permite reafirmar el carácter conmutable de ambas partículas.

Como puede desprenderse de los ejemplos precedentes, las partículas relevadas se adecúan al concepto de marcador del discurso, esto es, se comportan como unidades lingüísticas invariables que no ejercen una función sintáctica a nivel oracional y cuya función primordial es orientar las inferencias que se realizan en la comunicación. Por otro lado, dentro de esta categorización general corresponden al subtipo de los reformuladores, ya que se caracterizan por efectuar un movimiento retroactivo que le permite al hablante volver sobre un enunciado anterior para presentarlo de otra manera, con el propósito de que el interlocutor lo interprete adecuadamente (Garcés 2003 y 2011). En este sentido, en tanto reformuladores de distanciamiento, cumplen con las siguientes operaciones discursivas (Martín Zorraquino y Portolés 1999 y Portolés 2001):

a) presentar al segmento reformulado como no pertinente para la prosecución del discurso;

b) privar de pertinencia al segmento reformulado y asignarla al segmento reformulador;

c) mostrar el segmento reformulador como el que condiciona la prosecución del discurso.

Por otro lado, los marcadores igual y de todas maneras presentaron en nuestros materiales otros valores funcionales diferentes al aquí indagado. Así como también se indicó más arriba respecto de los ejemplos 2 y 6 , el empleo de igual como reformulador de distanciamiento contrasta con el valor gramatical de igual como adjetivo o adverbio comparativo de igualdad, que se ejemplifica en 9:

9. E: ya/ y ee y// ¿hái pasado alguna vez algún susto grande/ pero con tus hijos? así como/ como ¿hái tenido sustos de que algo les pase a tus hijos/ o a uno de los hijos?/ I: no/ fijate/ porque todo el tiempo/ yo cuando 
se iban/ me quedaba rezando/ igual que ahora cuando se va M. C. le digo yo que que vaya con Dios y la Santísima Virgen y las animitas del purgatorio/ que no les pase nada/ entonces y me quedo tan tranquila y cuando llega/ ya más relajada po (SCHI M31 032).

Otro de los valores funcionales determinados para el marcador de todas maneras, asimismo, es su empleo como respuesta afirmativa enfática, el que consiste en un uso no gramaticalizado (o mejor, "discursivizado") como marcador del discurso, tal como se ilustra en 10:

10. E: ya// y por ejemplo/ en relación a la televisión de antes y a la de ahora/ ¿la de antes era mucho más educativa en ese sentido/ o no? I: mm yo creo que eh más educativa ahora. E: ¿sí? I: sí/ de todas maneras (SCHI H22 050).

Para finalizar esta sección de análisis pragmático, además de la frecuencia del empleo de igual como reformulador de distanciamiento, cabe señalar que dicha partícula se caracteriza por su predisposición a combinarse con otros marcadores, como se ilustra en los ejemplos 11 al 13:

11. E: [...] ee ¿tú qué haces normalmente en tus vacaciones? I: [...] este año teníamos pensado salir de vacaciones/ sí o sí/ pero ee/ yo creo que no voy poder/ porque estoy con licencia/ estoy con un embarazo que es de riesgo/ entonces/ claramente no vamos a salir de vacaciones// una por/ por eso/ porque no puedo/ digamos médicamente/ y otro también por el/ por el tema plata/ porque igual tenemos que ahorrar para el nacimiento de los bebés po (SCHI M13 081).

12. E. y/y ¿qué opinas de las teleseries chilenas?/ por ejemplo/ en relación a las teleseries brasileñas/ que dicen que son tan buenas. I: o sea igual he visto teleseries chilenas/ pero claramente las brasileras son muy buenas/ muy buenas/ pero no/ no/ últimamente no he visto nada de eso (SCHI M13 081).

13. I: [...] estoy en otra etapa de mi vida ahora/ ee/ voy a hacer mamá el próximo año/ así que estoy esperando además gemelos/ entonces/ claramente mi tiempo va a tener que ir/ queramos o no/ digamos/ a/ a mi familia/ mis hijos/ a cuidarlos/ a verlos y eso/ a ser mamá/ cien por ciento. E: ¿pero/ sin dejar de trabajar? I: o sea si pudiera/ creo que lo haría/ aunque igual me gusta trabajar/ o sea/ mi ideal sería trabajar media jornada/ por ejemplo (SCHI M13 081). 


\subsection{ANÁLISIS SOCIOLINGÜÍSTICO DE LOS REFORMULADORES DE DISTANCIAMIENTO EN EL CORPUS PRESEEA-SA}

En nuestro corpus se identificó un total de 616 casos en los que se empleó la función "reformulador de distanciamiento". En el Gráfico 1 se muestra el porcentaje de frecuencia de los reformuladores de distanciamiento registrados en el corpus, entre los que destaca -por mucho- el empleo del marcador igual con un $97,8 \%$ de las preferencias, correspondiente a 602 casos. Le siguen, a considerable distancia, los marcadores de todas maneras (siete casos, $1,2 \%$ ), en todo caso (seis ocurrencias, $0,9 \%$ ) y de todas formas (un caso, 0,1\%). No obstante la claridad de las tendencias que puede desprenderse de estos datos estadísticos, cabe destacar el carácter preliminar y no definitivo de estas cifras, ya que solo se trata de la mitad del Corpus PRESEEA de Santiago de Chile.

Gráfico 1: Porcentaje de frecuencia de los reformuladores de distanciamiento en el corpus PRESEEA-SA

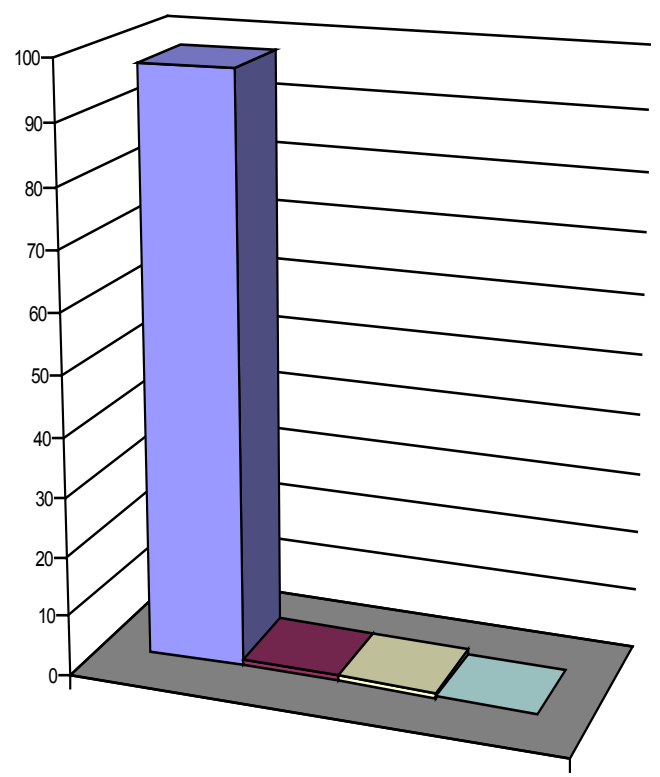

\begin{tabular}{|l|c|}
\hline$\square$ igual & 97,8 \\
\hline$\square$ de todas maneras & 1,2 \\
\hline$\square$ en todo caso & 0,9 \\
\hline$\square$ de todas formas & 0,1 \\
\hline
\end{tabular}


Por otro lado, por lo que se refiere al empleo de los reformuladores de distanciamiento y el sexo-género de los sujetos que conforman la muestra bajo análisis, en la Tabla 3 y el Gráfico 2, se ilustra la correlación entre dichas variables:

Tabla 3: Número y porcentaje de frecuencia de reformuladores de distanciamiento según sexo-género

Sexo-género

\begin{tabular}{|l|l|l|l|}
\hline \multicolumn{1}{|c|}{ Marcador } & \multicolumn{1}{c|}{ Hombres } & \multicolumn{1}{c|}{ Mujeres } & \multicolumn{1}{c|}{ Total } \\
\hline igual & $296(48,1 \%)$ & $306(49,7 \%)$ & $602(97,8 \%)$ \\
\hline de todas maneras & $3(0,5 \%)$ & $4(0,6 \%)$ & $7(1,2 \%)$ \\
\hline en todo caso & $3(0,5 \%)$ & $3(0,5 \%)$ & $6(0,9 \%)$ \\
\hline de todas formas & $1(0,1 \%)$ & $0(0 \%)$ & $1(0,1 \%)$ \\
\hline Total & $303(49,2 \%)$ & $313(50,8 \%)$ & $616(100 \%)$ \\
\hline
\end{tabular}

Gráfico 2: Porcentaje de frecuencia de los reformuladores de distanciamiento según sexo-género

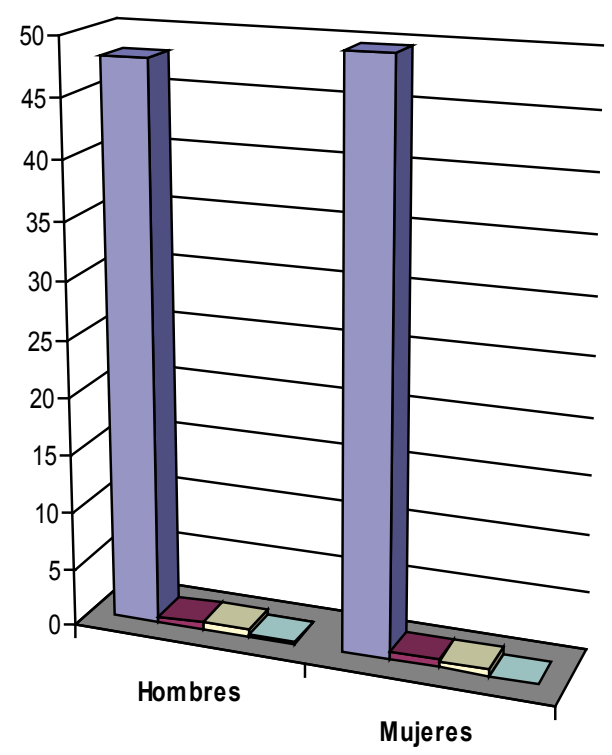

\begin{tabular}{|l|c|c|}
\cline { 2 - 3 } \multicolumn{1}{c|}{} & Hombres & Mujeres \\
\hline $\boldsymbol{\square}$ igual & 48,1 & 49,7 \\
\hline $\mathbf{\square}$ de todas maneras & 0,5 & 0,6 \\
\hline $\mathbf{Q}$ en todo caso & 0,5 & 0,5 \\
\hline $\mathbf{\square}$ de todas formas & 0,1 & 0 \\
\hline
\end{tabular}


Como se desprende de estas frecuencias relativas de empleo, no existen diferencias notables en cuanto al sexo-género de los sujetos que conforman la muestra. En especial, el empleo de igual, que como ya hemos destacado es el reformulador de distanciamiento por mucho más frecuente, es casi idéntico entre hombres y mujeres. En este sentido, el factor sexo-género no es determinante para el análisis cuantitativo de los marcadores aquí analizados.

Por otro lado, en la Tabla 4 y el Gráfico 3, se muestra la correlación entre el empleo de los reformuladores de distanciamiento y el grupo de edad de los sujetos, esto es, la variable etaria en estudio:

Tabla 4: Número y porcentaje de frecuencia de reformuladores de distanciamiento según grupo de edad

\begin{tabular}{|l|l|l|l|l|}
\hline \multicolumn{5}{|c|}{ Grupo de edad } \\
\hline Marcador & I (20-34) & II (35-54) & $\begin{array}{l}\text { I I I } \\
\text { más }\end{array}$ & y \\
\hline igual & $350(56,5 \%)$ & $202(32,8 \%)$ & $50(8,5 \%)$ & $602(97,8 \%)$ \\
\hline de todas maneras & $1(0,1 \%)$ & $1(0,1 \%)$ & $5(1 \%)$ & $7(1,2 \%)$ \\
\hline en todo caso & $2(0,3 \%)$ & $3(0,5 \%)$ & $1(0,1 \%)$ & $6(0,9 \%)$ \\
\hline de todas formas & $1(0,1 \%)$ & $0(0 \%)$ & $0(0 \%)$ & $1(0,1 \%)$ \\
\hline Total & $354(57 \%)$ & $206(33,4 \%)$ & $56(9,6 \%)$ & $616(100 \%)$ \\
\hline
\end{tabular}


Gráfico 3: Porcentaje de frecuencia de los reformuladores de distanciamiento según grupo de edad

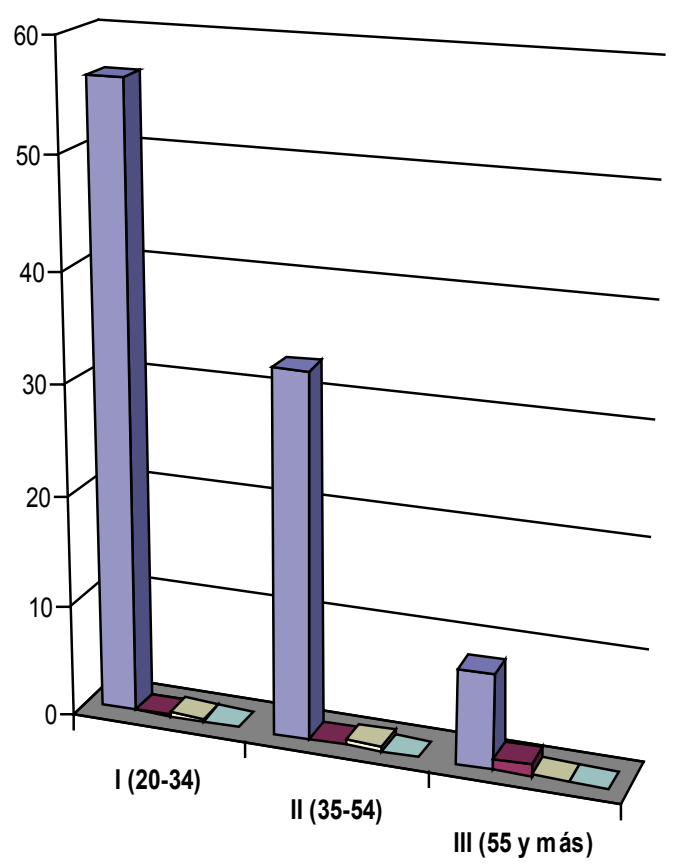

\begin{tabular}{|l|c|c|c|}
\cline { 2 - 4 } \multicolumn{1}{c|}{} & $\mathrm{I}(20-34)$ & $\mathbb{1}(35-54)$ & III (55 y más) \\
\hline $\mathbf{\square}$ igual & 56,5 & 32,8 & 8,5 \\
\hline $\mathbf{\square}$ de todas maneras & 0,1 & 0,1 & 1 \\
\hline $\mathbf{\square}$ en todo caso & 0,3 & 0,5 & 0,1 \\
\hline $\mathbf{\square}$ de todas formas & 0,1 & 0 & 0 \\
\hline
\end{tabular}

De acuerdo con estas frecuencias de empleo, el reformulador de distanciamiento igual es empleado -en lo fundamental-por los sujetos más jóvenes de la muestra (20 a 34 años), aunque no de modo exclusivo. Esta distribución de empleo configura un patrón de estratificación descendente, que en términos proporcionales va desde un uso mayoritario en el grupo I (20 a 34 años) hasta un empleo minoritario en el grupo III (55 y más años). Este aspecto del análisis cuantitativo es muy importante, ya que, al parecer, pese a que manejamos aquí solo porcentajes de frecuencia, es el factor etario el más sensible en el empleo de los reformuladores de distanciamiento relevados en la muestra. 
Por último, la Tabla 5 y el Gráfico 4 muestran las correlaciones entre el empleo de los reformuladores de distanciamiento y el nivel educacional de los sujetos que conforman la muestra de nuestro estudio:

Tabla 5: Número y porcentaje de frecuencia de reformuladores de distanciamiento según nivel educacional

\begin{tabular}{|l|l|l|l|l|}
\hline \multicolumn{5}{|c|}{ Nivel educacional } \\
\hline Marcador & Bajo & Medio & Alto & Total \\
\hline igual & $219(35,6 \%)$ & $304(49,4 \%)$ & $79(12,8 \%)$ & $602(97,8 \%)$ \\
\hline de todas maneras & $0(0 \%)$ & $0(0 \%)$ & $7(1,2 \%)$ & $7(1,2 \%)$ \\
\hline en todo caso & $2(0,3 \%)$ & $2(0,3 \%)$ & $2(0,3 \%)$ & $6(0,9 \%)$ \\
\hline de todas formas & $0(0 \%)$ & $0(0 \%)$ & $1(0,1 \%)$ & $1(0,1 \%)$ \\
\hline Total & $221(35,9 \%)$ & $306(49,7 \%)$ & $89(14,4 \%)$ & $616(100 \%)$ \\
\hline
\end{tabular}


Gráfico 4: Porcentaje de frecuencia de los reformuladores de distanciamiento según grupo de edad

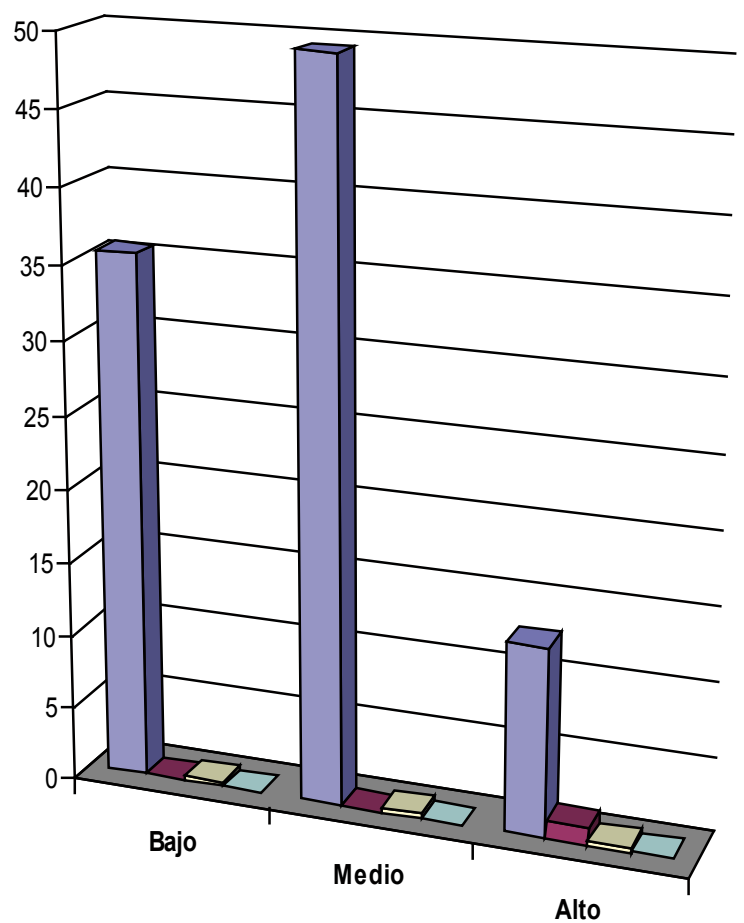

\begin{tabular}{|l|c|c|c|}
\cline { 2 - 4 } \multicolumn{1}{c|}{} & Bajo & Medio & Alto \\
\hline$\square$ igual & 35,6 & 49,4 & 12,8 \\
\hline$\square$ de todas maneras & 0 & 0 & 1,2 \\
\hline$\square$ en todo caso & 0,3 & 0,3 & 0,3 \\
\hline$\square$ de todas formas & 0 & 0 & 0,1 \\
\hline
\end{tabular}

En esta dimensión del análisis, los porcentajes de frecuencia manifiestan una preferencia en el empleo del reformulador de distanciamiento igual en los niveles de instrucción medio y bajo, configurando un patrón curvilíneo clásico con un empleo mayoritario en el nivel de estudios medio. Aunque el resto de los marcadores en análisis no manifiestan índices de frecuencia que nos permitan hacer comparaciones, es sintomático -a nuestro juicio-que en el nivel de instrucción alto se presente una mayor variedad de reformuladores de distanciamiento, si bien el empleo de igual sigue siendo preeminente. 
En términos generales, estos resultados son muy semejantes a los informados en San Martín (2004-2005), en el que se relevaron 554 instancias de la función variable "reformulación de distanciamiento", mediante la siguiente distribución de formas variantes (marcadores): igual (533 ocurrencias, correspondientes al 96,2\%), en todo caso (17 casos, con el $3 \%$ ) y de todas maneras (cuatro instancias, con el $0,8 \%$ ).

\section{CONCLUSIONES}

Las conclusiones más significativas del presente trabajo pueden sintetizarse como sigue:

1. En este estudio hemos considerado la función discursiva "marcador reformulador de distanciamiento" como un caso de variable lingüística -en un sentido amplio del concepto- a nivel de discurso, cuyo empleo se analizó en un corpus de 54 entrevistas del Proyecto PRESEEA correspondientes a una muestra del habla de Santiago de Chile.

2. En nuestro corpus se identificaron 616 ocurrencias de empleo de la función discursiva antes señalada, la que se concretó mediante cuatro formas variantes o valores con los siguiente números de ocurrencias y frecuencias de empleo: igual (602 ocurrencias, 97,8\%), de todas maneras (siete casos, $1,2 \%$ ), en todo caso (seis ocurrencias, $0,9 \%$ ) y de todas formas (un caso, $0,1 \%$ ).

3. Basándonos en la conmutabilidad funcional -pragmática y discursivade estos cuatro reformuladores en la muestra de discurso en estudio, procedimos al análisis cuantitativo de su empleo, según las variables: sexo, edad y nivel educacional, verificando la notoria preponderancia de igual con la función antes señalada, en contraste con las frecuencias de empleo de las otras tres formas variantes, tal como se indica precedentemente.

4. Los factores sociodemográficos que resultaron ser más sensibles en el empleo de los reformuladores de distanciamiento relevados fueron la edad y el nivel educacional de los sujetos cuyas entrevistas conformaron la muestra de discurso analizada.

5. El reformulador de distanciamiento igual está muy extendido en el habla de los sujetos más jóvenes de la muestra (entre 20 y 34 años). 
En nuestra opinión, tal vez, podría interpretarse la extensión del empleo de igual como reformulador de distanciamiento como un proceso de cambio lingüístico, en el cual dicho marcador parece estar desplazando a otras partículas que cumplen una función semejante. En apoyo a esta interpretación puede esgrimirse el factor edad como rasgo determinante.

6. El comportamiento de los reformuladores de distanciamiento relevados en la muestra, por lo que refiere tanto a su análisis pragmático como a la distribución sociolingüística de su empleo, es significativamente coincidente con los resultados informados en San Martín (2004-2005).

7. Para finalizar, cabe destacar el carácter necesariamente relativo de las conclusiones aquí sintetizadas, ya que se trata del procesamiento de solo la mitad del Corpus PRESEEA de Santiago de Chile.

\section{REFERENCIAS BIBLIOGRÁFICAS}

Blas Arroyo, José LuIs. 2005. Sociolingüistica del español. Desarrollos y perspectivas en el estudio de la lengua española en contexto social. Madrid: Cátedra.

Bosque, Ignacio y Violeta Demonte (eds.). 1999. Gramática descriptiva de la lengua española (3 volúmenes). Madrid: Espasa.

Brinton, Laurel y Elizabeth Closs Traugott. 2005. Lexicalization and Language Change. Cambridge, UK: Cambridge University Press.

Carbonero, Pedro y Catalina Fuentes (eds.). 1993. Sociolingüística Andaluza 8: estudios sobre el enunciado oral. Sevilla: Secretariado de Publicaciones de la Universidad de Sevilla.

Carbonero, Pedro y Juana Santana. 2010. Marcadores del discurso, variación dialectal y variación social. En Loureda y Acín (coords.), pp. 497-521.

COMPANY, CONCEPCiÓn. 2004. ¿Gramaticalización o desgramaticalización? El reanálisis y subjetivización de verbos como marcadores discursivos en la historia del español. Revista de Filología Española 84 (1): 29-66.

CoRTÉs, LuIs. 1998. Marcadores del discurso y análisis cuantitativo. En María Martín Zorraquino y Estrella Durán (coords.), pp. 143-160. Ágora. 1991. Sobre conectores, expletivos y muletillas en el español hablado. Málaga:

1995a. Bibliografía: marcadores del discurso (I). Español Actual 63: 63-82.

1995b. Bibliografía: marcadores del discurso (y II). Español Actual 64: 75-94.

DA: Asociación de Academias de la Lengua Española. 2010. Diccionario de Americanismos. Lima. Santillana Ediciones.

DUeCh: Academia Chilena de la Lengua. 2010. Diccionario de uso del español de Chile. Santiago: MN Editorial. 
FAnT, LARs. 2011. Modalización discursiva en el diálogo oral. En Lars Fant y Ana María Harvey (eds.). El diálogo oral en el mundo hispanohablante. Estudios teóricos y aplicados. Madrid/Frankfurt: Iberoamericana/Vervuert.

Fuentes, Catalina. 1993. Claro: modalización y conexión. En Carbonero y Fuentes (eds.), pp. 99-126.

1996. La sintaxis de los relacionantes supraoracionales. Madrid: Arco/Libros.

Garcés Gómez, María Pilar. 2003. Los marcadores de recapitulación y de reconsideración en el discurso. Revista de Investigación Lingüística 1 (6): 111-141.

2011. Procesos de reformulación en el discurso oral: corrección y rectificación. Español Actual 96: 89-106.

García, Erica. 1986. El fenómeno (de)queísmo desde una perspectiva dinámica del uso de la lengua. En José Moreno de Alba (ed.). Actas del II Congreso Internacional sobre El español de América. México: Universidad Nacional Autónoma de México, pp. 46-65.

Gili Gaya, Samuel. 1972. Curso superior de sintaxis española. Barcelona: Bibliograf.

González, Carlos, Meneses, Alejandra y Viviana Unda. 2000. Análisis de la relación entre estructuras sintácticas y marcadores discursivos en la conversación semiespontánea de adolescentes santiaguinos. Formulación de un proyecto de investigación. Onomázein 5: 333-346.

Hummel, Martin. 2012. Polifuncionalidad, polisemia y estrategia retórica. Los signos discursivos con base atributiva entre oralidad y escritura. Berlín: de Gruyter.

LaVAndera, Beatriz. 1978. Where does the sociolinguistic variable stop? Language in Society 7: $171-182$

Labov, William. 1972. Sociolinguistic Patterns. Philadelphia: University of Pennsylvania Press.

1978. Where does the sociolinguistics variable stop? A response to Beatriz Lavandera. Texas Working Papers in Sociolinguistics 44: 1-17.

Lenski, Gerhardt. 1954. Status Crystallization: A Non-vertical Dimension of Social Status. American Sociological Review 19: 405-413.

1956. Social Participation on Status Crystallization. American Sociological Review 21: 458-464.

López Morales, Humberto. 1994. Métodos de investigación lingüistica. Salamanca: Ediciones Colegio de España.

LOUREDA, ÓSCAR Y ESPERANZA Acín (coords.). 2010. Los estudios sobre marcadores del discurso, hoy. Madrid: Arco Libros.

Martín Zorraquino, María y Estrella Montolío Durán (coords.). 1998. Los marcadores del discurso. Teoría y análisis. Madrid: Arco Libros.

Martín Zorraquino, María y José Portolés. 1999. Los marcadores del discurso. En Ignacio Bosque y Violeta Demonte (eds.), pp. 4051-4207.

Meneses, Alejandra. 2000. Marcadores discursivos en el evento "conversación". Onomázein 5: 315-331.

Moreno Fernández, Francisco. 1998. Principios de sociolingüística y sociología del lenguaje. Barcelona: Ariel.

OBREgón, Hugo. 1985. Introducción a los marcadores interaccionales del habla dialogada en el español de Venezuela. Caracas: Centro de Investigaciones Lingüísticas y Literarias "Andrés Bello".

Pérez, MóniCA. 1998. Conectores discursivos en textos expositivos y argumentativos a nivel de parágrafo. Onomázein 3: 27-43. 
Poblete, María Teresa. 1998. Los marcadores discursivo-conversacionales de más alta frecuencia en el español de Valdivia (Chile). Estudios Filológicos 33: 93-103. 1999. La cohesión de los marcadores discursivos en distintos tipos de discurso. Estudios Filológicos 34: 165-180.

Pons, Hernán y José Luis SAmaniego. 1998. Marcadores pragmáticos de apoyo discursivo en el habla culta de Santiago de Chile. Onomázein 3: 11-25.

Pons, SAlvador. 1998. Oye y mira o los límites de la conexión. En María Martín Zorraquino y Estrella Durán (coords.): 213-228.

Portolés, José. 2001. Marcadores del discurso. Barcelona: Ariel.

Pons, Hernán y José Luis Samaniego. 1998. Marcadores pragmáticos de apoyo discursivo en el habla culta de Santiago de Chile. Onomázein 3: 11-25

Prieto Vera, Luis. 1995-1996. Análisis sociolingüístico del dequeísmo en el habla de Santiago de Chile. Boletín de Filología 35: 379-452.

Prieto Vera, Luis y Abelardo San Martín. 2002-2003. Diferencias de género en el empleo del discurso referido: aproximación sociolingüística y pragmático-discursiva. Boletín de Filología 39: 269-303.

Rabanales, Ambrosio y Lidia Contreras. 1991. Las muletillas en el habla culta de Santiago de Chile. En Elisabeth Luna Traill (coord.). Scripta Philologica in honorem Juan M. Lope Blanch, Vol. 2. México: UNAM, pp. 673-744.

Rodríguez, Yolanda. 1999. Marcadores discursivos en el habla de Barranquilla. Estudio sociolingüístico. Litterae. Revista de la Asociación de Exalumnos del Seminario Andrés Bello, No 8: 197-220.

Romaine, Suzane. 1981. The status of variable rules in sociolinguistic theory. Journal of Linguistics 17: 93-1 19.

San Martín, Abelardo. 2004-2005. Igual como marcador discursivo en el habla de Santiago de Chile: función pragmático-discursiva y estratificación social de su empleo. Boletín de Filología 40: 201-232.

2011. Los marcadores interrogativos de control de contacto en el corpus PRESEEA de Santiago de Chile. Boletín de Filología 46 (2): 135-166.

San Martín, Abelardo y Silvana Guerrero. 2013. Una aproximación sociolingüística al empleo del discurso referido en el corpus PRESEEA de Santiago de Chile. Revista Signos 46(82) (en prensa).

SANKOFF, DAVID. 1988. Sociolingüística y variación Sintáctica. En Frederick Newrneyer (ed.). Panorama de la lingüistica moderna. Madrid: Visor, pp. 140-161.

Schiffrin, Deborah. 2003. Discourse Markers: Language, Meaning and Context. The Handbook of Discourse Analysis. Oxford: Blackwell.

Serrano, María José. 1995. El uso de la verdad y pues como marcadores discursivos de respuesta. Español Actual 64: 5-16.

1999. Bueno como marcador discursivo de inicio de turno y contraposición. Internacional Journal of the Sociology of Language 14: 115-133.

2001. The socio-communicative function of two discourse markers in Spanish. Estudios de Sociolingüística 2 (1): 101-122.

2007. Historia que ya es historia: evolución y actualidad del concepto y metodología de la variación sintáctica. Boletín de Lingüistica 28: 102-127. 2011. Sociolingüistica. Barcelona: Ediciones del Serbal.

Silva-Corvalán, CARmen. 2001. Sociolingüística y pragmática del español. Washington, D. C.: Georgetown University Press. 